\title{
Eosinophilic Granuloma of the Mandible in a Four-year-old Boy - A Rare Case Report and Review of Literature
}

\author{
Jangbhadur Singh*, Afiya Shafi, Nadia Jeelani and Mabruka Jeelani
}

Shere Kashmir Institute of Medical Sciences Medical College Hospital, Pathology, Ram Bagh, Srinagar, India

*Correspondence: Jangbhadur Singh, Shere Kashmir Institute of Medical Sciences Medical College Hospital, Pathology, Ram Bagh, Srinagar, India, Tel: +919419032757; E-mail: jangbhadursinghsarna@gmail.com

\begin{abstract}
Eosinophilic Granuloma represents one of a triad, of lesions encompassing a disease under the generic name Histiocytosis X or Langerhans Cell Histiocytosis. It is a benign inflammatory reaction to an unknown etiological agent and corresponds with bony lesions. The most commonly involved bones are the skull, ribs and the femur. The cranium, maxilla and mandible can also be affected.

Keywords: Eosinophilic granuloma; Langerhans cell Histiocytosis; Oral manifestations; Bony lesions; Surgical curettage
\end{abstract}

Received Date: August 03, 2019; Accepted Date: August 29, 2019; Published Date: September 05, 2019

\section{Introduction}

Langerhans Cell Histiocytosis is a non-neoplastic granuloma like lesion of unknown origin characterized by proliferation of reticulohistiocytic structures, polynuclear eosinophils, neutrophils, lymphocytes, plasma cells, multinucleate giant cells and an abnormal and intense proliferation of Langerhans cells [1,2].

Langerhan Cell Histiocytosis can present as solitary or multiple lesions in one organ system (bone being the most common) or as a disseminated disease [3].

Most patients are children or adolescents but the disease can affect any age group, including the elderly [4]. It is classified into three clinical forms depending on the age and presentation:

1) Chronic focal Langerhans Cell Histiocytosis or Eosinophilic Granuloma - this is the most frequent and benign of the three clinical forms which appears as a unifocal or multifocal lesion in single or multiple bones with or without soft tissue involvement presenting at any age.

2) Chronic diffuse LCH (Hand Schuller Christian Disease) which usually appears in children or young adults with the characteristic triad of Exophthalmos, Osteolytic lesions of cranium and Diabetes insipidus.

Citation: Jangbhadur Singh, Eosinophilic Granuloma of the Mandible in a Four-year-old Boy - A Rare Case Report and Review of Literature. J Clin Cases Rep 3(2): 52-55. 
3) Acute disseminated LCH (Letterer Siwe disease) - affects the children under three years involving multiple organs and systems like liver, lung, lymph nodes, skin, bones and bone marrow. It has a fatal outcome in a short time [5-7].

In addition to this, lymph node involvement can be seen as a component of the systemic form or may represent the initial manifestation of the disease [8-10]. Oral manifestations may be the first sign of LCH and on some occasions oral cavity is the only affected area [11]. With curettage and roentgen therapy, the lesions begin to regress but without therapy regression is very slow [12].

\section{Case Report}

A four-year-old boy reported to the Dental OPD of our hospital with complaint of pain in the left mandibular region along with a well-defined swelling $(3 \mathrm{~cm} \times 3.5 \mathrm{~cm})$ in the same region. Swelling was extending from the left corner of the mouth to the angle of mandible and was bony hard in consistency. Intra oral examination revealed granular, friable and swollen gingiva. Ultrasonography revealed soft tissue area with necrosis seen in relation to the mandible and suggested a bony lesion (Figure $1 \mathrm{~A}-1 \mathrm{C})$.
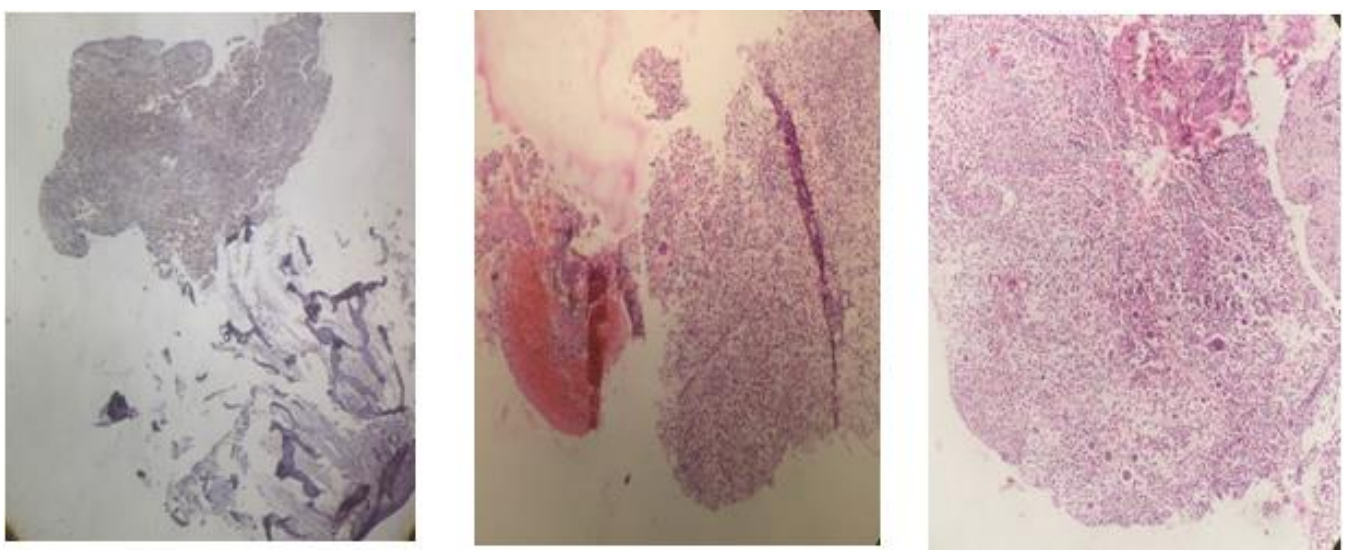

Figure 1A - 1C: Boney tissue along with neutrophils, eosinophils, histiocytes, langhan type giant cells in a necrotic background (A) 4X (B) $10 \mathrm{X}$ (C) $10 \mathrm{X}$

Intraoral radiographs revealed multiple multilocular well defined osteolytic lesions on the angle of the mandible extending up to the ramus. Complete haemogram showed a mild raise in the ESR. The differential leucocyte count revealed a moderately raised eosinophil count. Liver function and renal function tests were normal.

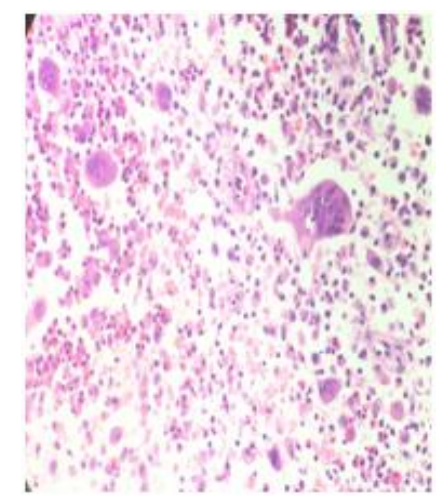

Figure 2: Langhan giant cells, histiocytes, abundant eosinophils, plasma cells and lymphocytes $20 \mathrm{X}$. 
http://www.tridhascholars.org | April-2020

Histopathological examination revealed fibro collagenous tissue and bony trabeculae infiltrated by focal collections of histiocytes, abundant eosinophils, plasma cells and lymphocytes. A few Langerhan cells with coffee-bean nuclei and increased vascularity were also observed rendering a diagnosis of Eosinophilic Granuloma (Figure 2).

After surgical intervention the lesions completely regressed and did not show any sign of recurrence during the follow up period.

\section{Discussion}

Approximately $10 \%$ to $20 \%$ of all cases of Eosinophilic Granuloma occur in the jaws [13]. A palpable mass with us without pain is the most frequent presenting clinical feature. Less common clinical signs include gingivitis, loose teeth and oral inflammation with poor healing. It may be clinically confused with focal infection, since patients may have slight fever, leukocytosis with eosinophilia and increased ESR [14]. It has been reported that males are more frequently affected than females with $75 \%$ of the lesions occurring as solitary lesions [15].

Radiographically, Eosinophilic Granuloma typically presents as punched out osteolytic lesions with or without periosteal reaction [14]. Around $10 \%$ of the patients with multifocal disease of the bone will develop multifocal and extraosseous disease.

A number of therapeutic options are available such as surgery, radiotherapy, chemotherapy and steroid injections. However, no therapy is required for localized osseous Eosinophilic Granuloma. Surgical curettage is enough to initiate healing and soft tissue regression [16].

In our case as the lesion was unifocal and localized to the jaws, we efficiently and successfully treated the child by surgical curettage of the lesion.

\section{Conclusion}

$\mathrm{LCH}$ is a rare disease and optimal management requires interdisciplinary collaboration between specialists (oral surgeon, dentist, ENT, radiologist, pathologist and oncologist). In case of osteolytic changes of the jaw bone LCH should be considered as a possible cause and biopsy should be sought to be established for a definitive diagnosis. Surgical treatment is effective in localized disease and causes spontaneous resolution.

\section{References}

1. Hefti F, Jundt G (1995) Langerhans cell histiocytosis. Der Orthopade 24(1): 73-81.

2. Pacino GA, Serrat A, Redondo LM, et al. (1999) Langerhans cell histiocytosis: clinical diagnostic features and current concepts. Medicina oral: organo oficial de la Sociedad Espanola de Medicina Oral y de la Academia Iberoamericana de Patologia y Medicina Bucal 4(5): 607-618.

3. Ornvold K, Nielsen MH, Clausen N (1985) Disseminated histiocytosis X: A clinical and immunohistochemical retrospective study. Acta Pathologica Microbiologica Scandinavica Series A: Pathology 93(1-6): 311-316.

4. Giona F, Caruso R, Testi AM, et al. (1997) Langerhans' cell histiocytosis in adults: a clinical and therapeutic analysis of 11 patients from a single institution. Cancer: Interdisciplinary International Journal of the American Cancer Society 80(9): 1786-1791. 
http://www.tridhascholars.org | April-2020

5. Duncan WK, Post AC, McCoy BP (1988) Eosinophilic granuloma. Oral Surgery, Oral Medicine, Oral Pathology, Oral Radiology 65(6): 736-741.

6. Becelli R, Carboni A, Gianni C, et al. (2002) A rare condition of Hand-Schüller-Christian disease. Journal of Craniofacial Surgery 13(6): 759-761.

7. Shaw L, Glenwright HD (1988) Histiocytosis X: an oral diagnostic problem. Journal of Clinical Periodontology 15(5): 312-315.

8. Motoi M, Helbron D, Kaiserling E, et al. (1980) Eosinophilic granuloma of lymph nodes-a variant of histiocytosis X. Histopathology 4(6): 585-606.

9. Reid H, Fox H, Whittaker JS (1977) Eosinophilic granuloma of lymph nodes. Histopathology 1(1): 31-37.

10. Williams JW, Dorfman RF (1979) Lymphadenopathy as the initial manifestation of histiocytosis X. The American Journal of Surgical Pathology 3(5): 405-421.

11. Sherly JC, Thonton JB (2000) Oral manifestation of LCH: review and report of case. ASDC Journal of Dentistry for Children 67: 293-296.

12. Kelley JH, McMillan JT (1962) Eosinophilic granuloma of bone: report of nine cases. Annals of Surgery 156(1): 147-150.

13. Holzhauer AM, Abdelsayed RA, Sutley SH (1999) Eosinophilic granuloma: A case report with pathologic fracture. Oral Surgery, Oral Medicine, Oral Pathology, Oral Radiology 87(6): 756-759.

14. Huysse WCJ, Hogendooen PCW, Loem JL, et al. (2006) Eosinophilic Granuloma of the skull. Journal of the Belgian Society of Radiology 89: 134-155.

15. Teplick JG, Boder H (1957) Eosinophilic granuloma of bone. American Journal of Roentgenology 78: 502.

16. Di Felice F, Zaina F, Donzelli S, et al. (2017) Spontaneous and complete regeneration of a vertebra plana after surgical curettage of an eosinophilic granuloma. European Spine Journal 26(1): 225-228. 